\title{
Phenotypic complementation of genetic immunodeficiency by chronic herpesvirus infection
}

\author{
Donna A MacDuff1, Tiffany A Reese ${ }^{1}$, Jacqueline M Kimmey², Leslie A Weiss', \\ Christina Song ${ }^{1}$, Xin Zhang ${ }^{1}$, Amal Kambal', Erning Duan', Javier A Carrero', \\ Bertrand Boisson ${ }^{3,5}$, Emmanuel Laplantine ${ }^{4}$, Alain Israel ${ }^{4}$, Capucine Picard ${ }^{5,6,7,9,10,}$ \\ Marco Colonna1, Brian T Edelson ${ }^{1}$, L David Sibley², Christina L Stallings ${ }^{2}$, \\ Jean-Laurent Casanova ${ }^{3,5,7,9,10}$, Kazuhiro Iwai ${ }^{8}$, Herbert W Virgin ${ }^{1 *}$
}

1Department of Pathology and Immunology, Washington University School of Medicine, St Louis, United States; ${ }^{2}$ Department of Molecular Microbiology, Washington University School of Medicine, St Louis, United States; ${ }^{3}$ Howard Hughes Medical Institute, New York, United States; ${ }^{4}$ Laboratory of Molecular Signaling and Cell Activation, Institut Pasteur, Centre National de la Recherche Scientifique, Unité de Recherche Associée, Paris, France; ${ }^{5}$ St Giles Laboratory of Human Genetics of Infectious Disease, Rockefeller University, New York, United States; ${ }^{6}$ Study Center for Primary Immunodeficiency, Necker Hospital for Sick Children, Paris, France; ${ }^{7}$ Laboratory of Human Genetics of Infectious Diseases, Necker Branch, Necker Hospital for Sick Children, Imagine Institute, INSERM UMR 1163, Paris, France; ${ }^{8}$ Department of Molecular and Cellular Physiology, Graduate School of Medicine, Kyoto University, Kyoto, Japan; ${ }^{9}$ Paris Descartes University, Paris, France; ${ }^{10}$ Pediatric Hematology-Immunology Unit, Necker Hospital for Sick Children, Paris, France

Abstract Variation in the presentation of hereditary immunodeficiencies may be explained by genetic or environmental factors. Patients with mutations in HOIL1 (RBCK1) present with amylopectinosis-associated myopathy with or without hyper-inflammation and immunodeficiency. We report that barrier-raised HOIL-1-deficient mice exhibit amylopectin-like deposits in the myocardium but show minimal signs of hyper-inflammation. However, they show immunodeficiency upon acute infection with Listeria monocytogenes, Toxoplasma gondii or Citrobacter rodentium. Increased susceptibility to Listeria was due to HOIL-1 function in hematopoietic cells and macrophages in production of protective cytokines. In contrast, HOIL-1-deficient mice showed enhanced control of chronic Mycobacterium tuberculosis or murine y-herpesvirus 68 (MHV68), and these infections conferred a hyper-inflammatory phenotype. Surprisingly, chronic infection with MHV68 complemented the immunodeficiency of HOIL-1, IL-6, Caspase-1 and Caspase-1;Caspase-11-deficient mice following Listeria infection. Thus chronic herpesvirus infection generates signs of auto-inflammation and complements genetic immunodeficiency in mutant mice, highlighting the importance of accounting for the virome in genotype-phenotype studies.

DOI: 10.7554/eLife.04494.001

\section{Introduction}

HOIL-1 (encoded by the RBCK1 gene), HOIP (RNF31) and SHARPIN form the linear ubiquitin chain assembly complex (LUBAC), which linearly ubiquitinates receptor signaling complex components such as NEMO to enhance NF-KB activation after engagement of immune receptors including TNF-R1, IL-1R, 
eLife digest The immune system protects an individual from invading bacteria, viruses and parasites, as well as malfunctioning or cancerous host cells. However, some people inherit genetic defects that cause part of the immune system to be missing or to not work properly. This is called a genetic immunodeficiency, and puts individuals at a higher risk of infection and disease.

The symptoms of immunodeficiencies can vary substantially between individuals, even when they have defects in the same gene. For example, only some of the individuals who have defects in both of their copies of a gene called HOIL-1-which has been linked to several roles in the body's immune response-are reported to suffer from an altered susceptibility to bacterial infections and chronic (persistent) inflammation. Gaining a clear understanding of the possible factors that influence such variations in the symptoms of genetic immune deficiencies could help to speed up their diagnosis, as well as helping to develop more effective treatments.

MacDuff et al. studied mice that had mutations in both copies of the mouse equivalent of the HOIL-1 gene. These mice, when raised in a clean barrier facility that reduces their exposure to viruses, were severely immunodeficient and died when infected by certain bacteria and parasites, including Listeria monocytogenes. However, they were able to tolerate infections with a herpesvirus or the bacterium that causes tuberculosis. The immunodeficiency to $L$. monocytogenes was linked to problems producing protective molecules called cytokines, which form a crucial part of the immune response. Unexpectedly, MacDuff et al. found that a chronic herpesvirus infection substantially protected these very immunodeficient animals from infection with Listeria monocytogenes, and the mice were able to efficiently produce protective cytokines.

Mice with two other distinct genetic deficiencies that affect their immune system were also better able to survive otherwise lethal bacterial infections if they had a long-term herpesvirus infection. Macduff et al. suggest that the chronic herpesvirus infection stimulates the immune system, and so allows it to compensate for the lack of cytokine production associated with various immunodeficiencies, including those caused by mutations in the HOIL-1 gene. This suggests that the presence of viruses or other long-term infections may be responsible for some of the variability seen in the symptoms of different individuals with the same genetic immunodeficiency. This is an important concept since essentially all humans have life-long chronic infections from various herpesviruses, as well as other viruses that form the human virome.

DOI: 10.7554/eLife.04494.002

CD40, TLRs and NOD2 (Tokunaga et al., 2011; Tokunaga et al., 2009; Ikeda et al., 2011; Gerlach et al., 2011; Haas et al., 2009; Zak et al., 2011; Hostager et al., 2011; Boisson et al., 2012; Damgaard et al., 2012; Tian et al., 2007). Recently, HOIL-1/LUBAC was also shown to be important for activation of the NLRP3/ASC inflammasome in macrophages via linear ubiquitination of ASC (Rodgers et al., 2014). These data suggest that HOIL-1 plays multiple roles in inflammation and infection. In mice, SHARPIN deficiency results in auto-inflammation involving multiple organs including the liver, esophagus, lung and, most noticeably, chronic proliferative dermatitis of the skin (Seymour et al., 2007). The development and organization of secondary lymphoid organs and antibody isotype switching are also impaired in these mice (HogenEsch et al., 1999). Loss of HOIP catalytic activity in $\mathrm{B}$ cells results in the impaired development of B1 B cells and antibody responses to antigen (Sasaki et al., 2013). However, HOIL-1-deficient mice have not been analyzed extensively to date.

Sixteen patients with bi-allelic mutations in the gene encoding HOIL-1 have been reported (Boisson et al., 2012; Nilsson et al., 2013; Wang et al., 2013). Three patients exhibited cardiomyopathy, amylopectinosis, hyper-inflammation and mild immunodeficiency associated with an increased frequency of bacterial infections, whereas other patients presented with amylopectinosis and myopathy alone (Figure 1-figure supplement 1). The role of HOIL-1 in inflammation and immunity to infection in vivo is, therefore, uncertain.

Although there are multiple possible explanations for the variable clinical presentations of the reported patients including hypomorphic expression of HOIL-1 or effects of mutations on protein function, another possibility was that environmental factors alter the clinical presentation of HOIL-1 deficiency. In this study we define the function of HOIL-1 in murine immunity to infection and explore the potential role of the virome in determining HOIL-1 deficiency-associated phenotypes. 
The bacterial microbiome and the virome regulate inflammation and immunity (Virgin, 2014; Virgin et al., 2009; Belkaid and Hand, 2014). Within the virome, herpesviruses persistently infect most humans, and exert significant effects on innate immunity in mice during experimental chronic infection, including increasing resistance to tumors and a range of pathogens (Barton et al., 2007; White et al., 2010; Yager et al., 2009; Nguyen et al., 2008; Haque et al., 2004). However, the potential effects of chronic infection on the phenotypic manifestations of immune deficiencies have not been considered.

In this study, we show that chronic herpesvirus infection can alter the presentation of several genetic immunodeficiencies in mice. We first found that, in naïve mice, HOIL-1 is essential during infection with Listeria monocytogenes, Toxoplasma gondii and Citrobacter rodentium and for efficient induction of pro-inflammatory cytokines that are known to be essential for resistance to lethal infection by hematopoietic cells during Listeria infection. In contrast, HOIL-1 knock-out (KO) mice, with null mutations in the Rbck1 gene that encodes HOIL-1, were resistant to infection with murine $\mathrm{Y}$-herpesvirus 68 (MHV68) and Mycobacterium tuberculosis. Although HOIL-1 KO mice raised in a barrier facility did not display signs of auto-inflammation, chronic infection with MHV68 or M. tuberculosis resulted in elevated inflammatory cytokines circulating in the serum, similar to that observed in some patients with mutations in RBCK1 (HOIL1). Interestingly, latent infection with MHV68 rescued HOIL-1 deficient mice from lethality during Listeria infection and induced high levels of the protective cytokine, interferongamma (IFNY). MHV68 latency also protected IL-6, Caspase-1 and Caspase-1;Caspase-11 deficient mice from Listeria-induced lethality, indicating that the ability of latent infection to complement a genetic immunodeficiency is not restricted to mutation of Hoil-1. These data indicate that chronic infections can modify the clinical presentations of genetic variations, thereby opening a new avenue for the analysis and interpretation of human genotype-phenotype association studies. We speculate that the protective effect of chronic herpesvirus infection is due to the stimulation of the function of the innate immune system in a manner that compensates for deficient early cytokine responses associated with multiple immunodeficiencies.

\section{Results}

\section{HOIL-1 is essential during acute infection with Listeria monocytogenes, Citrobacter rodentium and Toxoplasma gondii}

HOIL-1 KO mice (Tokunaga et al., 2009) were born at Mendelian ratios and, in contrast to SHARPINdeficient mice, failed to develop TNFa-driven inflammatory skin disease (Ikeda et al., 2011; Gerlach et al., 2011; Tokunaga et al., 2011; Tokunaga and Iwai, 2012) and exhibited normal histology of lymphoid organs, liver, lung, and kidney, and the presence of Peyer's patches along the small intestine (not shown). Aged HOIL-1 KO mice exhibited deposits of material that stained with periodic acidSchiff reagent and was resistant to digestion with diastase, similar to the amylopectin-like material observed in humans with HOIL-1 deficiency (Figure 1-figure supplement 2) (Boisson et al., 2012). Importantly, these barrier-raised mice showed minimal signs of baseline hyper-inflammation. In this regard, HOIL-1 KO mice exhibited normal numbers of lymphoid and myeloid cells in the spleen and thymus, normal complete blood counts (Figure 1-figure supplement $3 A, B, D$ ), and no detectable increase of tumor necrosis factor alpha (TNFa) or interleukin 6 (IL-6) in serum (discussed below). However, in the peritoneum, HOIL-1 KO mice contained about twofold more B cells, T cells and resident macrophages without changes in other cell types (Figure 1-figure supplement 3C). Expression of neighboring genes, Trib3 and Tbc1d20, was unaffected by disruption of the Rbck1 (Hoil1) gene (Figure 1-figure supplement 4).

To determine the requirement for HOIL-1 during the immune response to infection in vivo, we challenged HOIL-1 KO mice with a number of different pathogens. Strikingly, HOIL-1 KO mice were highly susceptible to even low dose infection with the facultative gram-positive intracellular bacterium, Listeria monocytogenes (Listeria), with $80 \%, 80 \%$ and $50 \%$ of mice succumbing to infection within 10 days of intraperitoneal (i.p.) inoculation with $10^{5}, 10^{4}$ and $10^{3} \mathrm{CFU}$, respectively (Figure 1A). Although bacterial burdens in the spleens and livers of control and HOIL-1 KO mice were similar 1 and 3 days post-infection with $10^{5}$ CFU, bacterial CFUs were elevated in HOIL-1 KO mice by 6 days post-infection, indicating that HOIL-1 KO mice were unable to control and clear the bacteria (Figure 1B). Further, these mutant mice developed large inflammatory lesions in the liver, elevated liver enzymes in the serum, and widespread tissue destruction in the spleen (Figure 1figure supplement 5 , not shown). 


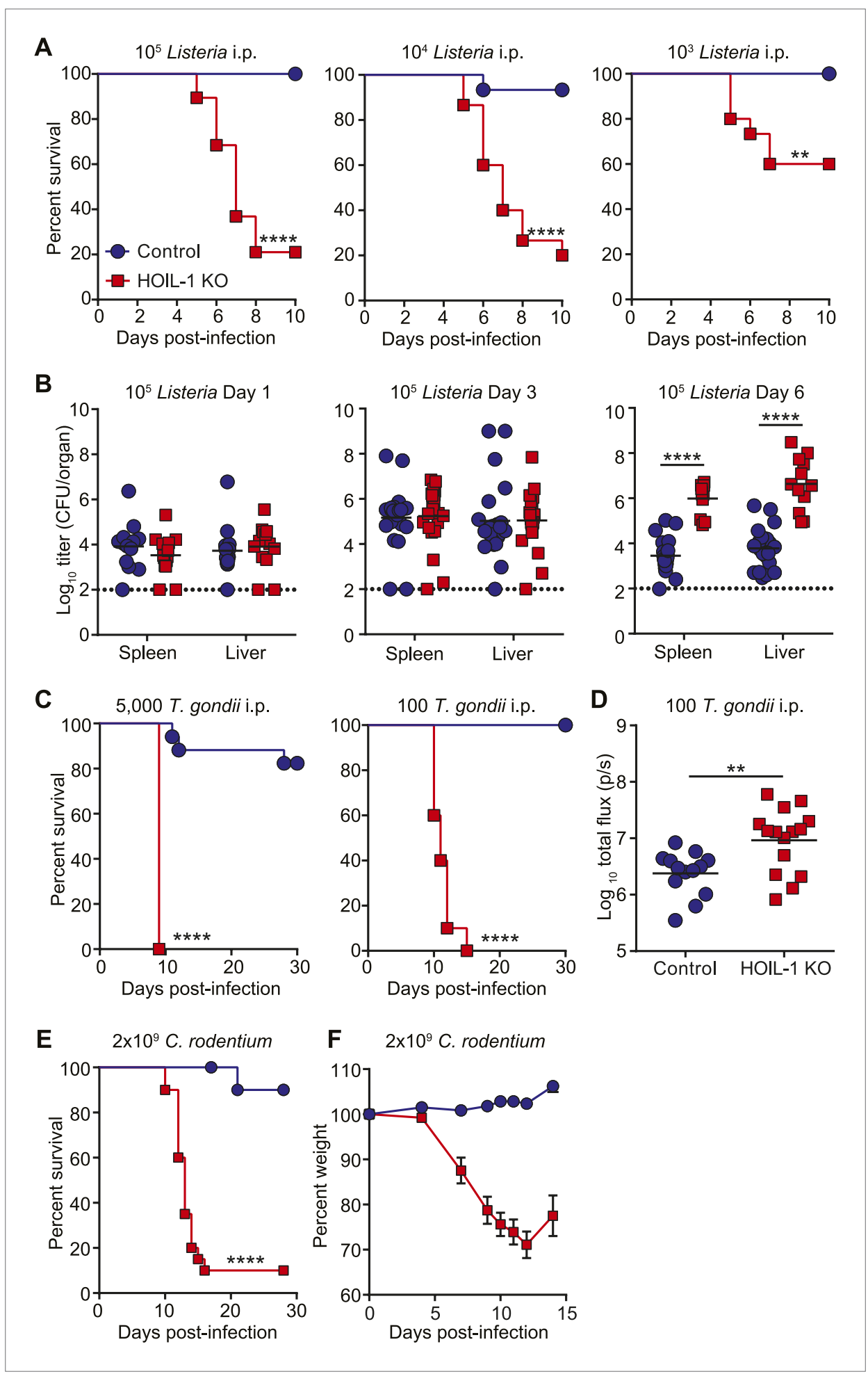

Figure 1. HOIL-1 KO mice are highly susceptible to acute infection with Listeria monocytogenes, Toxoplasma gondii and Citrobacter rodentium. (A) Survival of control (blue circles) and HOIL-1 KO (red squares) mice following i.p. inoculation with $10^{5}$ (left panel; control $n=35$, HOIL-1 KO $n=19$ ), $10^{4}$ (middle panel; control $n=15$, HOIL-1 KO $n=15$ ) or $10^{3}$ (right panel; control $n=15$, HOIL-1 KO $\left.n=15\right)$ CFU Listeria strain EGD. (B) Listeria CFU in spleen and liver from control (blue circles) and HOIL-1 KO (red squares) mice infected with 105 CFU i.p. for 1 day (left panel), 3 days (middle panel) or 6 days (right panel). Each symbol represents an individual mouse and the mean $\log _{10}$ CFU is indicated. The dashed line indicates the limit of detection. (C) Survival of control (blue circles) and HOIL-1 KO (red squares) Figure 1. Continued on next page 
Figure 1. Continued

mice following inoculation with 5000 (left panel; control $n=17$, HOIL-1 KO $n=5$ ) or 100 (middle panel; control $n=10, \mathrm{HOIL}-1 \mathrm{KO} n=10$ ) tachyzoites T. gondii strain Pru-luc. (D) $\log _{10}$ total flux (luciferase activity; photons per second) as a measure of parasite burden 8 days post-infection with 100 tachyzoites. Each symbol represents an individual mouse and the mean $\log _{10}$ is indicated. $(\mathbf{E}, \mathbf{F})$ Survival $(\mathbf{E})$ and weight $(\mathbf{F})$ of control (blue circles) and HOIL-1 $\mathrm{KO}$ (red squares) mice following oral gavage with $2 \times 10^{\circ} \mathrm{CFU}$ C. rodentium. $\mathrm{n}=20 /$ group for survival and $\mathrm{n}=10 / \mathrm{group}$ for weight. ${ }^{*} p \leq 0.05,{ }^{* *} p \leq 0.01,{ }^{* *} p \leq 0.001,{ }^{* * *} p \leq 0.0001$. Statistical analyses were performed using logrank Mantel-Cox test (A, C and $\mathbf{E})$, Mann-Whitney test (B), or t-test (D).

DOI: 10.7554/eLife.04494.006

The following figure supplements are available for figure 1:

Figure supplement 1. Comparison of RBCK1/HOIL1 alleles from RBCK1/HOIL1-mutant patients. DOI: 10.7554/eLife.04494.007

Figure supplement 2. Myocardium from aged HOIL-1 KO mice contains amylopectin-like deposits. DOI: 10.7554/eLife.04494.008

Figure supplement 3. Analysis of hematopoietic cell populations from naïe HOIL-1 KO mice. DOI: 10.7554/eLife.04494.009

Figure supplement 4. Hoil1/Rbck1 and neighboring gene (Trib3 and Tbc1d20) transcript expression in control and HOIL-1 KO bone marrow derived macrophages.

DOI: 10.7554/eLife.04494.010

Figure supplement 5. Pathology of HOIL-1 KO mice during Listeria infection. DOI: 10.7554/eLife.04494.011

HOIL-1 KO mice were also highly susceptible to infection with a relatively avirulent type II strain of the intracellular apicomplexan parasite Toxoplasma gondii (T. gondii) (Figure 1C). Despite infection with 5000 parasites resulting in lethality in only $20 \%$ of control mice, 100 parasites was sufficient to induce lethality in $100 \%$ of HOIL-1 KO mice. Quantification of parasite-encoded luciferase expression in vivo revealed that HOIL-1 KO mice failed to control T. gondii replication by 8 days post-infection (Figure 1D). HOIL-1 KO mice also succumbed to infection with the enteric gram-negative pathogen Citrobacter rodentium, whereas control mice were highly resistant (Figure 1E,F). These data indicated that loss of HOIL-1 expression confers profound immunodeficiency in barrier-raised mice.

\section{HOIL-1 is essential in bone marrow-derived innate immune cells during acute Listeria infection}

To define the role of HOIL-1 in immunity, we examined the response to Listeria in more detail. One patient with HOIL-1-associated immunodeficiency showed signs of recovery from hyper-inflammation after hematopoietic stem cell transplantation (Boisson et al., 2012). In mice, reciprocal bone marrow transplantation revealed that expression of HOIL-1 in radiation-sensitive hematopoietic cells was critical for resistance to Listeria (Figure 2A, Figure 2-figure supplement 1). We noted that control mice that received control bone marrow were slightly more susceptible to infection than non-irradiated control mice (compare with Figure 1A), suggesting that reconstitution does not fully restore the immune system of a lethally irradiated mouse to that of a non-irradiated animal. Despite this caveat, irradiated wild-type control mice that received HOIL-1 KO bone marrow and were challenged with $10^{5}$ Listeria 8 weeks later succumbed to infection at the same rate as HOIL-1 KO mice that had received HOIL-1 KO bone marrow. HOIL-1 KO mice that received control bone marrow had an increased survival rate, but still succumbed more readily than control mice that received control bone marrow. These data indicate that, while HOIL-1 expression is essential in bone marrow-derived cells, HOIL-1 may also play a role in radiation resistant cells during Listeria infection.

To determine whether HOIL-1 deficiency resulted in a defect in innate or adaptive immunity, we bred the HOIL-1 KO mice onto a RAG1-deficient background. T and B cell-deficient RAG1 HOIL-1 double $\mathrm{KO}$ mice succumbed to infection significantly faster than RAG1 KO mice (Figure 2B), and exhibited elevated bacterial burden in the spleen and liver 3 days post-infection (Figure 2C), indicating that HOIL-1 plays an essential role in innate immunity during Listeria infection. Indeed, HOIL-1-deficient mice succumbed to infection at the same rate regardless of the presence or absence of the adaptive immune system (compare Figures $1 \mathrm{~A}$ and 2B). Further, HOIL-1 KO mice immunized with a low dose of Listeria were capable of mounting a protective adaptive response to a high dose secondary challenge with Listeria 28 days later (Figure 2-figure supplement 2). We noted that 1000 CFU administered i.p. was 


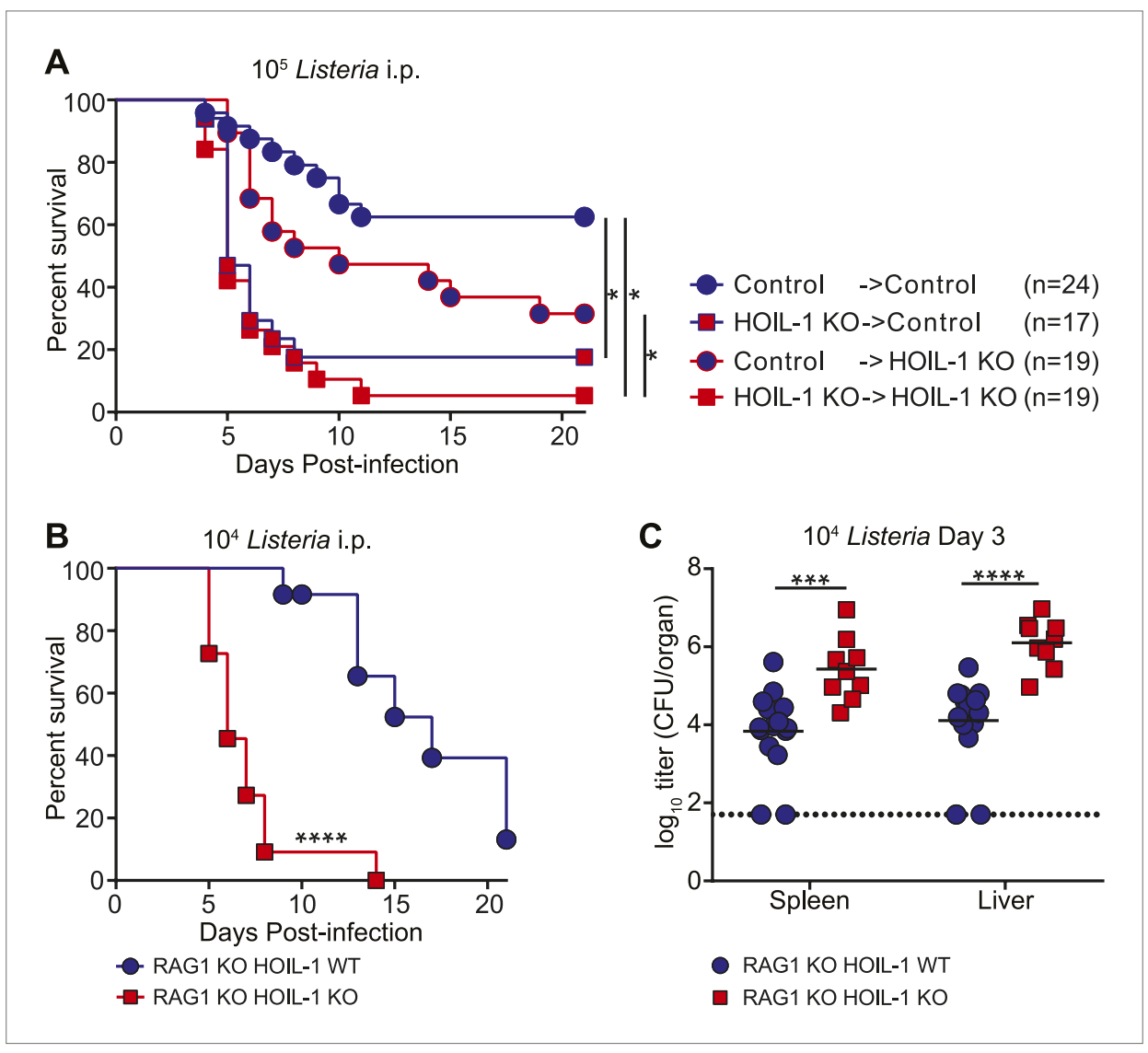

Figure 2. HOIL-1 is required in an innate immune cell compartment during Listeria infection. (A) Survival of control and HOIL-1 KO reciprocal bone marrow chimeric mice following infection with $10^{5} \mathrm{CFU}$ Listeria. ${ }^{*} \mathrm{p} \leq 0.0083$; logrank Mantel-Cox test corrected for multiple comparisons. (B) Survival of RAG1 KO HOIL-1 WT (blue circles; $n=12$ ) and RAG1 KO HOIL-1 KO (red squares; $n=11$ ) mice following infection with $10^{4} \mathrm{CFU}$ Listeria. (C) Listeria CFU in spleen and liver from RAG1 KO HOIL-1 WT (blue circles) and RAG1 KO HOIL-1 KO (red squares) mice infected with $10^{4} \mathrm{CFU}$ for 3 days. Each symbol represents an individual mouse and the mean $\log _{10}$ is indicated. For $\mathbf{B}$ and $\mathbf{C}$, ${ }^{\star} p \leq 0.05,{ }^{* \star} p \leq 0.01,{ }^{* \star *} p \leq 0.001,{ }^{* \star *} p \leq 0.0001$; logrank Mantel-Cox test and Mann-Whitney test, respectively. DOI: 10.7554/eLife.04494.012

The following figure supplements are available for figure 2:

Figure supplement 1. Confirmation of hematopoietic reconstitution of bone marrow chimeric mice. DOI: 10.7554/eLife.04494.013

Figure supplement 2. HOIL-1 KO mice are capable of generating an adaptive immune response to Listeria. DOI: 10.7554/eLife.04494.014

a borderline dose required to successfully immunize control mice in our experiments, despite being sufficient to induce lethality in 50\% of HOIL-1 KO mice (Figure 1A). Together, these data do not rule out a role for HOIL-1 in adaptive immunity, but show that HOIL-1 plays a major role in hematopoietic cells to foster innate immunity to Listeria infection.

\section{HOIL-1 is required for efficient production of pro-inflammatory cytokines by macrophages in response to Listeria infection}

Innate immunity to Listeria in mice depends on tissue-resident macrophages and CD8 $\alpha^{+}$dendritic cells responding to Listeria infection by secreting pro-inflammatory cytokines including TNFa, IL-12, and IL-6. These cytokines are each well recognized to be essential for survival after Listeria infection (Unanue, 1997; Williams et al., 2012) through their role in coordinating activation of NK cells, NKT cell and T cells to produce IFNY required for the bactericidal activity of phagocytic cells. Therefore, to further define a role for HOIL-1 in the innate immune system, we determined whether HOIL-1 KO bone marrow-derived macrophages (macrophages herein) produced cytokines in response to Listeria infection with or without IFNy treatment. Compared to control cells, HOIL-1 KO macrophages secreted 
only $50 \%, 20 \%$ and $10 \%$ of the expected levels of TNFa, IL-6 and IL-12p70 protein, respectively (Figure 3A). Consistent with a role for HOIL-1 in the activation of the NF-KB transcription factor following TLR stimulation, Listeria-infected HOIL-1 KO macrophages expressed decreased levels of Tnf, 116 and $1 / 12 \mathrm{~b}$ mRNA (Figure 3B). The defects in cytokine transcript levels were of smaller magnitude than the decreases in secreted protein, particularly for Tnf, suggesting that HOIL-1 may also be involved in cytokine translation or secretion. However, HOIL-1 KO macrophages killed Listeria after activation with IFNy as effectively as control cells, indicating the selectivity of HOIL-1 effects on macrophage function (Figure 3-figure supplement 1).

We confirmed that induction of Tnf and 116 mRNA was significantly impaired following Listeria infection in vivo by measuring cytokine transcripts in peritoneal cells from mice 3 to $12 \mathrm{hr}$ after infection (Figure $3 C$ ). This reduction in cytokine transcripts could not be explained by a decrease in macrophage numbers (Figure 3-figure supplement 2). Surprisingly, II12b transcript levels were similar in HOIL-1 $\mathrm{KO}$ mice, with a significant difference being detected at only $6 \mathrm{hr}$ after infection. Similar decreases in Tnf and 116 mRNA were observed in mice on the Rag $1^{-/-}$background at $3 \mathrm{hr}$ post-infection, confirming that these differences are due to a defect in innate immunity in the absence of HOIL-1 (Figure 3figure supplement 3). We also noted that fewer NK cells and neutrophils were present in the peritoneum $6 \mathrm{hr}$ after Listeria infection, suggesting delayed recruitment or proliferation of these cell types (Figure 3-figure supplement 2). These decreases in cytokine production and delayed cell recruitment likely synergize with defects in IL-1 $\beta$ and TNFa signaling observed by others (Tian et al。, 2007; Haas et al., 2009; Tokunaga et al., 2009, 2011) to compromise antibacterial immunity, and may contribute to the impaired induction of Ifng mRNA observed by $12 \mathrm{hr}$ (Figure 3C). These data indicate that HOIL-1 plays a critical role in coordinating essential early cytokine responses after Listeria infection.

\section{HOIL-1 KO mice display enhanced control of murine gamma-herpesvirus 68 and Mycobacterium tuberculosis and a hyperinflammatory response to infection}

The above data demonstrate that HOIL-1 KO mice have a severe immunodeficiency after certain types of infection. To assess the generality of this phenotype we infected HOIL-1 KO mice with murine Y-herpesvirus 68 (MHV68), a genetic relative of the common persistent human herpesviruses, EpsteinBarr virus and Kaposi's sarcoma-associated herpesvirus (EBV, KSHV) (Barton et al., 2011; Speck and Ganem, 2010). HOIL-1 KO mice survived MHV68 infection for at least 3 months. MHV68 replication was unaffected by HOIL-1 deficiency in cultured macrophages, and was suppressed only slightly in vivo (Figure 4-figure supplement 1). Despite normal establishment of latency as determined by the number of cells carrying MHV68 genome 28 days after infection (Figure 4-figure supplement 2), the efficiency of MHV68 reactivation from latency in explanted peritoneal cells was significantly impaired (approximately 50-fold, Figure 4A). Similarly, HOIL-1 KO mice failed to succumb to infection with M. tuberculosis over 70 days of infection, and in fact exhibited lower bacterial colony counts in the spleen while counts in the lung were no different than controls (Figure 4B). Thus HOIL-1 KO mice are fully able to control, and may have an enhanced ability to control, specific aspects of acute and chronic MHV68 and M. tuberculosis infection, in striking contrast to the immunodeficiency apparent after infection with Listeria, Toxoplasma, and Citrobacter.

\section{Environmental control of HOIL-1 deficiency-associated phenotypes}

The ability of HOIL-1 KO mice to effectively control chronic herpesvirus infection allowed us to test the hypothesis that persistent virus infection might alter two phenotypes, hyper-inflammation and immunodeficiency, in which HOIL-1 KO mice appear to differ from some reported patients with bi-allelic mutations in RBCK1 (HOIL1) (Boisson et al., 2012). Notably, patients with HOIL-1 deficiency and hyper-inflammation exhibited increased expression of IL-6 and TNFa in the serum and increased expression of mRNA for 116 in blood cells (Boisson et al., 2012). We therefore examined the serum of MHV68-infected HOIL-1 KO mice for cytokines essential for resistance to Listeria but deficient in Listeria-infected HOIL-1 KO mice. As previously observed (Barton et al., 2007), latent infection of control mice with MHV68 was associated with an increase in circulating levels of TNFa, IL-6, IL-12 and IFNy compared with uninfected mice (Figure 4C). In HOIL-1 KO mice, MHV68 latently resulted in small but significant increases in TNFa, IL-6 and IL-12p70 levels, and a more striking increase in IFNy levels compared to latently infected controls. HOIL-1 KO mice chronically infected with $M$. tuberculosis also exhibited increased expression of both IL-6 and TNFa in serum at 70 days post-infection (Figure 4D). 


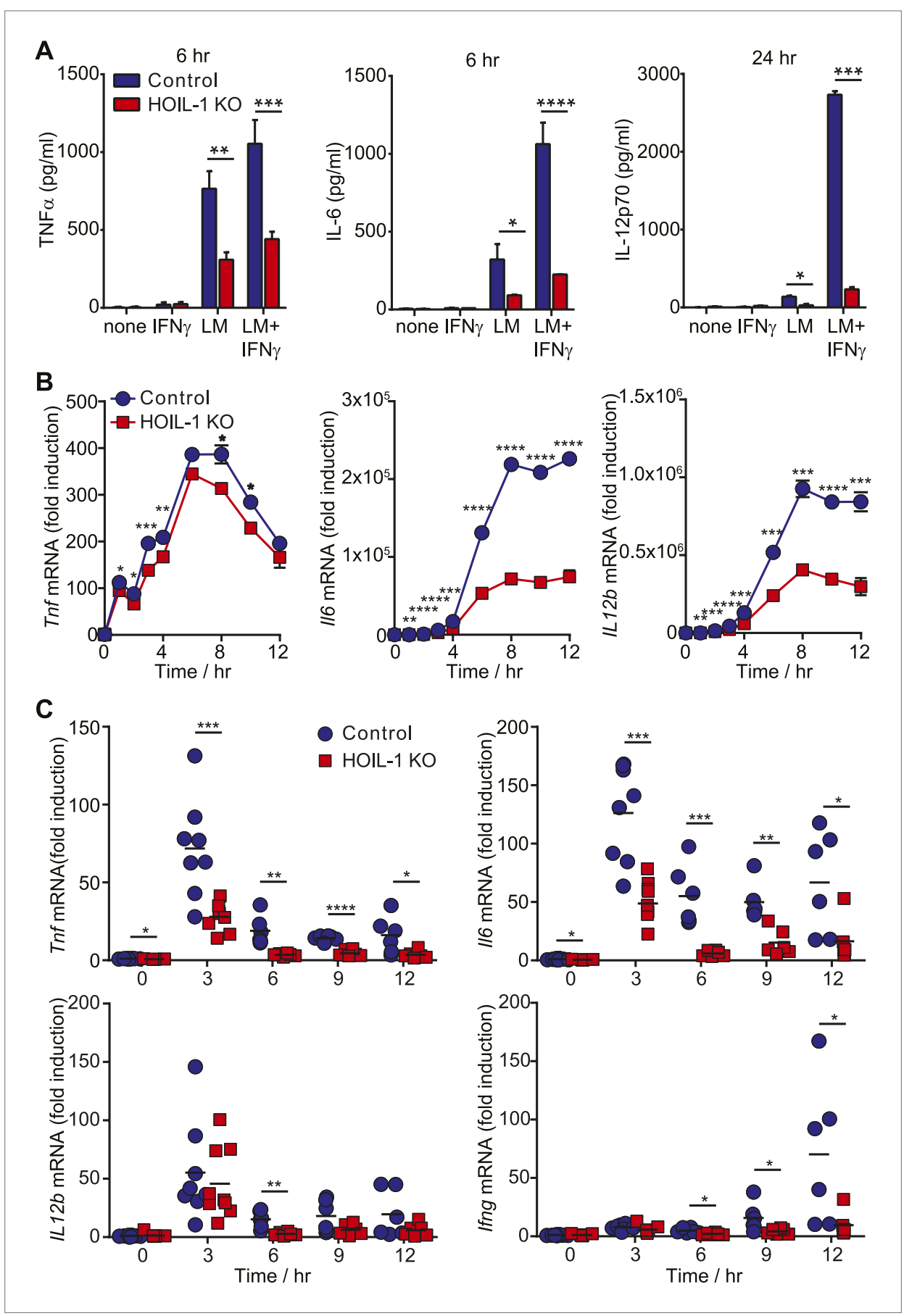

Figure 3. HOIL-1 is important for induction of pro-inflammatory cytokines following Listeria infection. (A) TNFa (6 hr), IL-6 $(6 \mathrm{hr})$ and IL-12p70 (24 hr) protein in macrophage culture supernatants following infection with Listeria (LM) \pm IFNy co-treatment. (B) Induction of Tnf, 116 and $1 / 12 \mathrm{~b}$ transcripts in macrophages over $12 \mathrm{hr}$ following infection with Listeria plus IFNy. Data represent the mean \pm SEM of macrophages derived from two mice per genotype analyzed in triplicate and are representative of at least three independent experiments. (C) Induction of cytokine transcripts in peritoneal cells over $12 \mathrm{hr}$ following infection of control (blue circles) and HOIL-1 KO (red squares) mice with $10^{5}$ Listeria. Each symbol represents an individual mouse. ${ }^{\star} p \leq 0.05,{ }^{* \star} p \leq 0.01,{ }^{* \star *} p \leq 0.001,{ }^{* \star \star *} p \leq 0.0001$. Statistical analyses were performed using $t$-test. DOI: $10.7554 /$ LLife.04494.015

The following figure supplements are available for figure 3:

Figure supplement 1. HOIL-1 is not required for listericidal activity of bone marrow-derived macrophages. DOI: 10.7554/eLife.04494.016

Figure 3. Continued on next page 
Figure 3. Continued

Figure supplement 2. Analysis of peritoneal cell populations following Listeria infection. DOI: 10.7554/eLife.04494.017

Figure supplement 3. HOIL-1 is important for induction of pro-inflammatory cytokines by innate cells following Listeria infection in vivo.

DOI: 10.7554/eLife.04494.018

Therefore, there is an overlap between cytokines expressed in hyper-inflammatory patients and in chronically-infected HOIL-1 KO mice.

\section{Latent infection with murine gamma-herpesvirus 68 protects HOIL-1 deficient mice from Listeria-induced lethality}

MHV68 latency has been shown previously to induce symbiotic protection against Listeria infection in wild-type mice (Barton et al., 2007). Because expression of TNFa, IL-6 and IFNY are essential for control of Listeria infection in mice (Kopf et al., 1994; Unanue, 1997; Williams et al., 2012), and were impaired in Listeria-infected HOIL-1 KO mice (Figure 3C), but elevated in MHV68-infected HOIL-1 KO mice, we considered whether chronic MHV68 infection could complement the profound immunodeficiency observed in Listeria-infected barrier-raised HOIL-1 KO mice. As observed previously (Barton et al., 2007), MHV68 latency, 1 month after infection, protected control mice from an otherwise lethal dose of Listeria (Figure 5A). MHV68 latency also protected HOIL-1 KO mice from a dose of Listeria at least 1000-fold higher than the $\mathrm{LD}_{50}$ for MHV68-negative mice (Figures 5A and 1A). Both control and HOIL-1 KO mice were still partially protected from Listeria challenge 6 months after MHV68 infection (Figure 5-figure supplement 1). A viral mutant capable of acute lytic infection but unable to efficiently establish latency (ORF73.stop) (Moorman et al., 2003) was unable to efficiently protect HOIL-1 KO or control mice from Listeria infection, demonstrating that latent MHV68 is required to complement HOIL-1-associated immunodeficiency to Listeria (Figure 5B).

\section{Mechanism of virus-associated protection of HOIL-1 KO mice}

To determine whether MHV68 latency rescued pro-inflammatory cytokine induction by HOIL-1 KO mice following Listeria infection, we quantitated cytokine transcripts in peritoneal cells from latently infected mice before (Figure 5C) and $3 \mathrm{hr}$ after (Figure 5D) infection with Listeria. As predicted from the cytokine levels in the serum, MHV68 latency resulted in small but significant increases in Tnf, Il6 and II12b transcripts prior to Listeria challenge (Figure 5C). While MHV68 latency did not rescue the induction of Tnf or 116 transcripts in HOIL-1 KO mice following infection with Listeria, /12b transcript levels were increased approximately twofold, and were comparable to levels in control mice. More significantly, Ifng and Nos2 (encoding iNOS) transcripts were elevated approximately 200-fold and 1000-fold, respectively, in latently infected control and HOIL-1 KO mice (Figure 5C), and further induced by $3 \mathrm{hr}$ after infection with Listeria (Figure 5D). Ifng transcript levels were significantly higher in latently infected HOIL-1 KO mice following infection with Listeria than in control mice. These data suggest that MHV68 latency by-passes the requirement for TNFa and IL-6 during early Listeria infection by enhancing the induction of IFNY and downstream effector molecules important for controlling Listeria infection.

To test whether peritoneal macrophages from latently infected HOIL-1 KO mice had an increased capacity to kill Listeria, we explanted peritoneal macrophages from mock or latently infected mice, infected them with Listeria, killed extracellular bacteria with gentamycin treatment, and compared the number of CFU at $6 \mathrm{hr}$ to the number of CFU at the beginning of the experiment. As expected, cells from mock infected control mice exhibited mild listericidal activity and cells from latently infected control mice had an enhanced ability to kill Listeria (Figure 5-figure supplement 2, (Barton et al., 2007)). Macrophages from mock-infected HOIL-1 KO mice had a slightly impaired ability to control Listeria infection. However, MHV68 latency in HOIL-1 KO mice enhanced the ability of macrophages to kill Listeria, generating a capacity to kill similar to that observed with macrophages from control mice. Together, these data suggest that MHV68 latency induces an environment that enhances the ability of HOIL-1-deficient cells to kill and respond to Listeria.

\section{Viral complementation of multiple genetic immunodeficiencies}

To determine whether the viral complementation of immunodeficiency was unique to HOIL-1, we latently infected IL-6, Caspase-1-deficient and Caspase-1;Caspase-11-double-deficient mice 


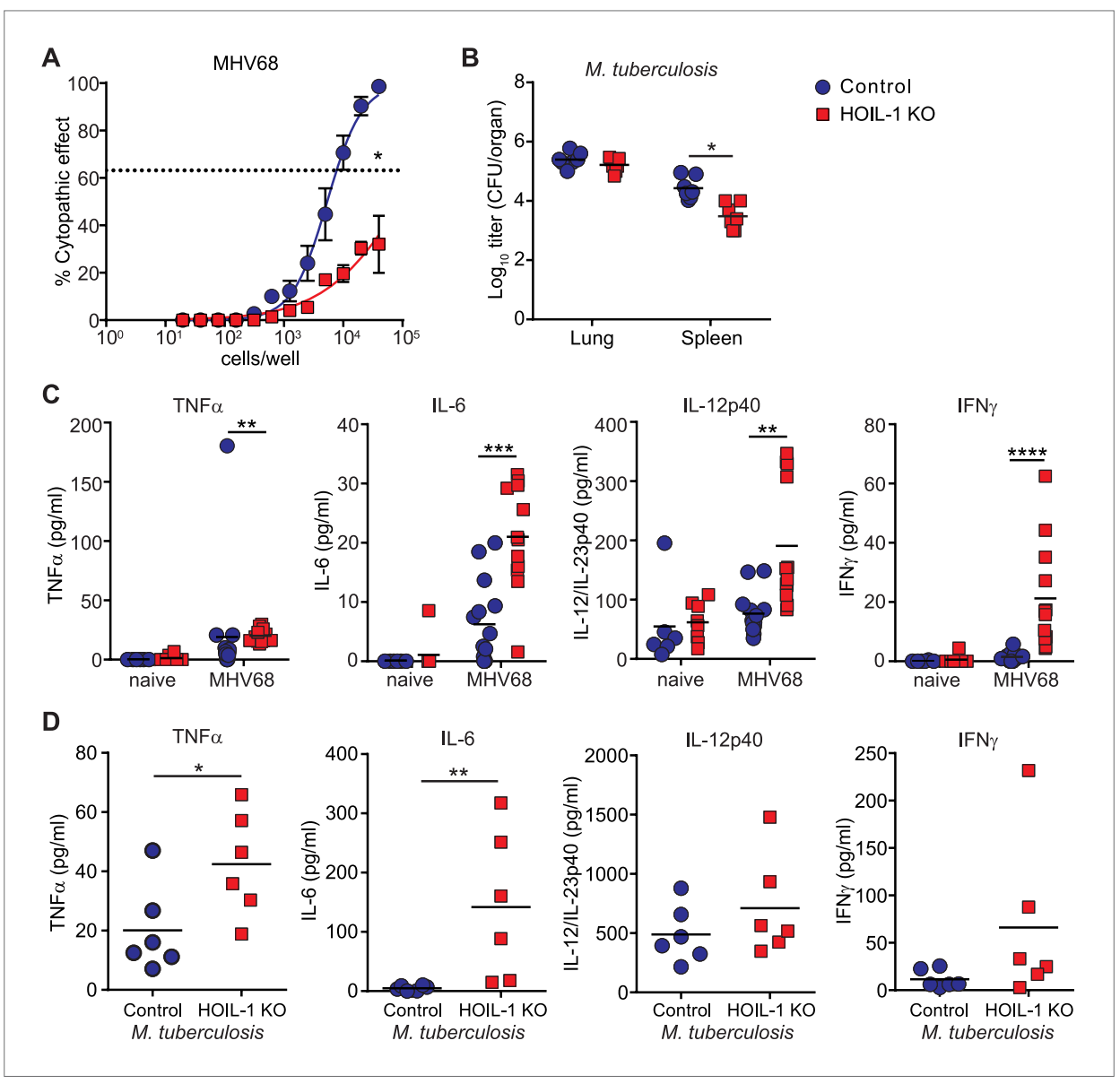

Figure 4. Enhanced inflammatory response and control of MHV68 and M. tuberculosis by HOIL-1 KO mice. (A) Limiting dilution assay of peritoneal cells from control (blue circles) and HOIL-1 KO (red squares) mice infected with MHV68 for 28 days onto mouse embryonic fibroblast monolayers to measure the frequency of cells capable of MHV68 reactivation. The dashed line indicates $63.2 \%$, which was used to determine the frequency of cells reactivating virus by the Poisson distribution. Data represent the mean from three independent experiments each with cells combined from three mice/group. ${ }^{*} p \leq 0.05$. Statistical analyses were performed by calculating the number of control and HOIL-1 KO cells required for $63.2 \%$ of wells to contain complete cytopathic effect for each individual experiment by non-linear regression, then comparing these values by paired t-test. Preformed virus was not detected in disrupted samples (not shown). (B) M. tuberculosis titers in the lung and spleen of HOIL-1 KO (red squares) and control (blue circles) mice 70 days post-infection. ${ }^{*} p \leq 0.05$. Statistical analyses were performed using t-test. (C) TNFa, IL-6, IL-12/IL-23p40 and IFNy protein detected in serum from naïve or latently-infected (28 days) control (blue circles) and HOIL-1 KO (red squares) mice. Each symbol represents an individual mouse and the mean is indicated. ${ }^{*} p \leq 0.05, t$-test with Welch's correction (IL-12/IL-23p40) or Mann Whitney test (TNFa, IL-6, IFNy). (D) TNFa, IL-6, IL-12/IL-23p40 and IFNy protein in serum from mice from (B). Each symbol represents an individual mouse. Data are combined from two independent experiments. ${ }^{*} p \leq 0.05,{ }^{* \star} p \leq 0.01$. Statistical analyses were performed using $t$-test (TNFa, IL-12p40) with Welch's correction (IFNy) or Mann Whitney test (IL-6).

DOI: 10.7554/eLife.04494.003

The following figure supplements are available for figure 4:

Figure supplement 1. Acute MHV68 replication in vitro and in vivo is minimally affected by HOIL-1-deficiency. DOI: 10.7554/eLife.04494.004

Figure supplement 2. Establishment of MHV68 latency is similar in control and HOIL-1 KO mice. DOI: 10.7554/eLife.04494.005

(Kayagaki et al., 2013), which survive MHV68 infection but are all highly susceptible to Listeria infection (Figure 5-figure supplement 3) (Kopf et al., 1994; Sarawar et al., 1998; Edelson and Unanue, 2002; Tsuji et al., 2004; Sauer et al., 2011). IL-6, Caspase-1 and Caspase-1;Caspase-11-deficient mice were also protected from lethality following Listeria infection by chronic MHV68 infection (Figure 5E,F). 


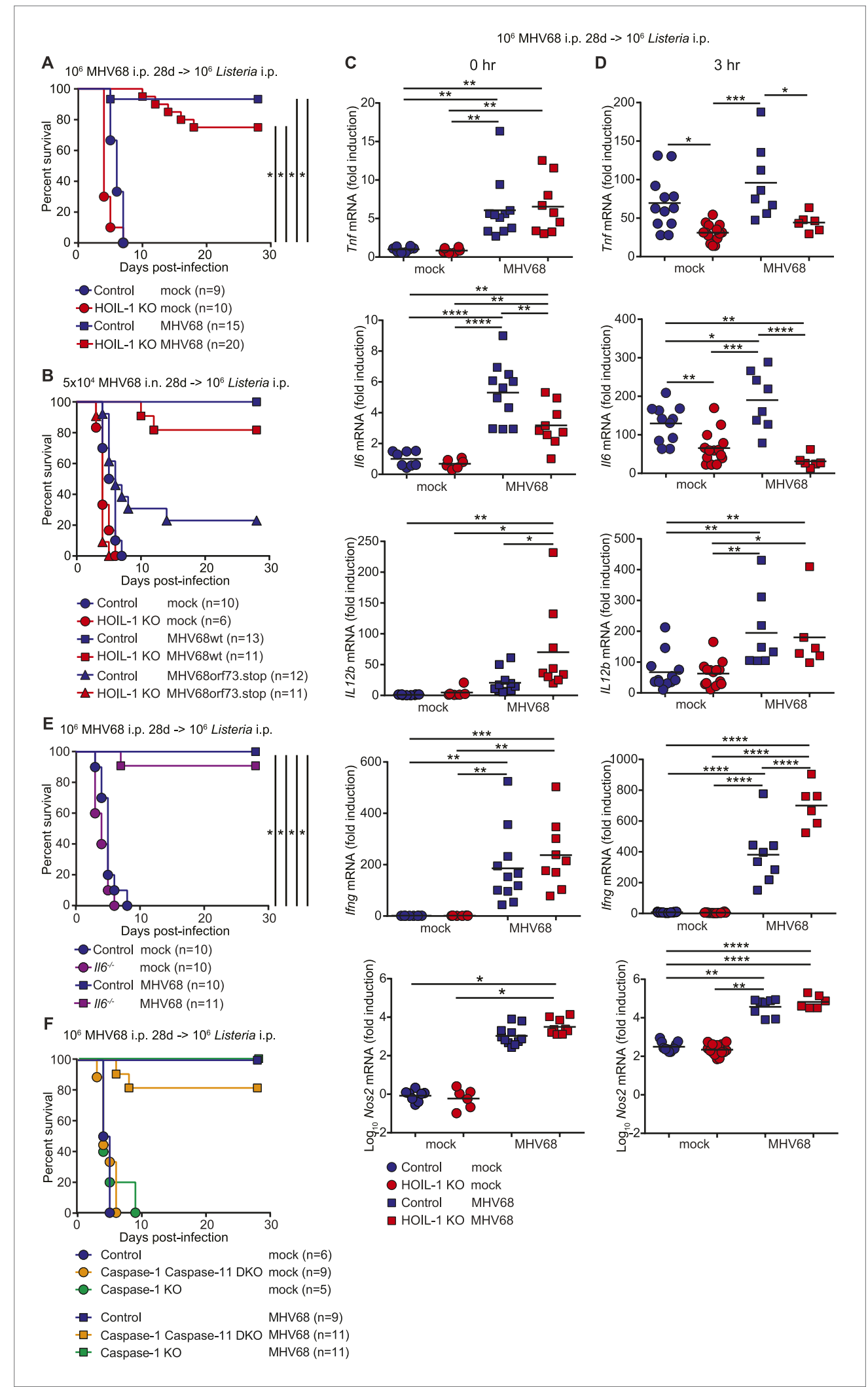

Figure 5. MHV68 latency rescues HOIL-1 KO, IL-6, Caspase-1 and Caspase-1;Caspase-11-deficient mice from Listeria-induced lethality. (A) Survival of control (blue symbols; mock $n=9$, MHV68 $n=15$ ) and HOIL-1 KO (red symbols; mock $n=10$, MHV68 $n=20$ ) mice challenged with $10^{6}$ CFU Listeria 28 days following mock infection (circles) or Figure 5. Continued on next page 
Figure 5. Continued

infection with $10^{6}$ PFU MHV68 (squares). * $p \leq 0.0083$; logrank Mantel-Cox test corrected for multiple comparisons. (B) Survival of control (blue symbols) and HOIL-1 KO (red symbols) mice challenged with $10^{6}$ CFU Listeria 28 days following intranasal mock infection (circles) or infection with $5 \times 10^{4} \mathrm{PFU}$ wild-type (squares) or ORF73.stop (triangles) MHV68. Significantly different groups were: control mock infected and control MHV68wt infected, control mock infected and HOIL-1 KO MHV68wt infected, control mock infected and HOIL-1 KO MHV68orf73.stop infected, HOIL-1 KO mock infected and control MHV68wt infected, HOIL-1 KO mock infected and HOIL-1 KO MHV68wt infected, control MHV68wt infected and control MHV68orf73.stop infected, control MHV68wt infected and HOIL-1 KO MHV68orf73.stop infected, HOIL-1 KO MHV68wt infected and control MHV68orf73.stop infected, HOIL-1 KO MHV68wt infected and HOIL-1 KO MHV68orf73.stop infected, control MHV68orf73.stop infected and HOIL-1 KO MHV68orf73.stop infected. ${ }^{*} p \leq 0.0033$; logrank Mantel-Cox test corrected for multiple comparisons. (C) Cytokine transcript levels in peritoneal cells from mock (circles) and MHV68-infected (squares) control (blue symbols) and HOIL-1 KO (red symbols) mice (28 days post-infection). (D) Induction of cytokine transcripts in peritoneal cells from mock (circles) and MHV68-infected (squares) control (blue symbols) and HOIL-1 KO (red symbols) mice (28 days) $3 \mathrm{hr}$ after infection with $10^{5}$ Listeria. Each symbol represents an individual mouse. For (C) and (D), * $p \leq 0.05,{ }^{* *} p \leq 0.01$, ${ }^{* * *} p \leq 0.001,{ }^{* * *} p \leq 0.0001$. Statistical analyses were performed using one-way ANOVA. (E) Survival of control (blue symbols) and $116^{-/-}$(purple symbols) mice challenged with $10^{6} \mathrm{CFU}$ Listeria 28 days following mock infection (circles) or infection with $10^{6} \mathrm{PFU}$ MHV68 (squares). ${ }^{*} \mathrm{p} \leq 0.0083$; logrank Mantel-Cox test corrected for multiple comparisons. (F) Survival of control (blue symbols), Caspase-1;Caspase-11 (orange symbols) and Caspase-1 (green symbols) -deficient mice challenged with $10^{6}$ CFU Listeria 28 days following mock infection (circles) or infection with $10^{6}$ PFU MHV68 (squares). * $\mathrm{p} \leq 0.0033$; logrank Mantel-Cox test corrected for multiple comparisons.

DOI: 10.7554/eLife.04494.019

The following figure supplements are available for figure 5:

Figure supplement 1. MHV68 latency-induced cross-protection is maintained for at least 6 months. DOI: 10.7554/eLife.04494.020

Figure supplement 2. MHV68 latency enhances the listericidal activity of peritoneal macrophages. DOI: $10.7554 /$ eLife.04494.021

Figure supplement 3. $116^{-/-}$mice have increased susceptibility to Listeria infection.

DOI: 10.7554/eLife.04494.022

These data indicate that the capacity of chronic MHV68 to reverse a significant immunodeficiency is not restricted to mutations in Rbck1 (Hoil1), and suggest that chronic viral infections may alter phenotypes of many host allelic variants.

\section{Discussion}

We report that HOIL-1 is essential during infection with Listeria, T. gondii and C. rodentium, but not with MHV68 or M. tuberculosis in mice. Expression of HOIL-1 was critical in innate, hematopoieticderived cells during Listeria infection in vivo. The requirement of HOIL-1 for the induction of protective inflammatory cytokines, TNFa, IL-6 and IL-12, following infection of macrophages with Listeria in vitro is consistent with reports that LUBAC is required for efficient NF-KB activation following TLR engagement (Zak et al., 2011; Boisson et al., 2012), but not with a recent report that NF-KB activation following stimulation of TLR4 and TNF-R1 on macrophages by LPS and TNFa, respectively, is unaffected by HOIL-1 deficiency (Rodgers et al., 2014). These apparently conflicting results suggest that HOIL-1 and LUBAC may not only have cell-type specific functions (Boisson et al., 2012; Rodgers et al., 2014), but also stimulus-specific roles that vary between different cell types. This may be further highlighted by the excessive inflammatory response and enhanced control of MHV68 and M. tuberculosis infectiontwo pathogens that also infect macrophages-by HOIL-1-deficient mice. It has been proposed that low levels of viral reactivation during MHV68 latency are responsible for the low level of constant immune activation and cytokine production (Barton et al., 2007). It is paradoxical, then, that reactivation is almost undetectable in HOIL-1-deficient animals, and yet their inflammatory response is elevated. Since the negative regulator of NF-KB signaling, A20, binds to linear ubiquitin chains (Tokunaga et al., 2012; Verhelst et al., 2012), HOIL-1/LUBAC may also be important for recruiting A20 to receptor signaling complexes to turn off signaling. Therefore, receptor signaling may be sustained in cells in HOIL-1 KO mice, resulting in the increase in TNFa, IL-6 and IL-12, and ultimately IFNy protein, observed in the serum of chronically infected mice. Decreased viral reactivation may be the result of this increased IFNy, the inability of latently infected cells to response to a stimulus of reactivation or a combination thereof. 
It is unclear why HOIL-1 KO mice are extremely susceptible to some pathogens, yet control other infections remarkably well. This might be due to HOIL-1/LUBAC having differential roles in transducing signals from different immune sensors stimulated by different infections. Other possibilities include a differential requirement for the innate immune system to hold the acute infection in check while an adaptive response is being generated, the speed at which the pathogen replicates, the tissues that it damages, and whether pathology during acute infection is mostly immune- or pathogen-derived. Further studies will be required to address these possibilities.

We further show that chronic infection with MHV68 rescued HOIL-1, IL-6, Caspase-1 and Caspase1; Caspase-11-deficient mice from lethal Listeria infection, thereby masking the genetic immunodeficiency observed in MHV68-negative mice. As reported previously (Barton et al., 2007), MHV68 latency was associated with increased basal levels of pro-inflammatory cytokines TNFa, IL-6, IL-12 and IFNy in the serum of wild-type animals, which were further increased in HOIL-1 KO mice. These cytokines appear to increase the activation status of the innate immune system such that their induction following Listeria infection is no longer as important as would be the case in a naïve mouse. Indeed, MHV68 infection did not enhance the transcription of Tnf, and only marginally enhanced the transcription of $1 / 6$ and $/ 112 \mathrm{~b}$ even in control mice following Listeria infection, and did not rescue the defect in Tnf and 116 induction observed in HOIL-1 KO mice. Conversely, transcription of Ifng and the effector molecule, iNOS (encoded by Nos2), was elevated in cells from latently infected mice and enhanced substantially by both HOIL-1 $\mathrm{KO}$ and control animals very rapidly following infection with Listeria. Macrophages require priming with IFNy to induce IL-12 in response to Listeria infection. In a latently infected animal, IFNy is already present and so IL-12 and additional IFNy may be induced more rapidly. Furthermore, as reported previously for wild-type mice (Barton et al., 2007), MHV68 latency enhanced the ability of peritoneal macrophages from control and HOIL-1 KO mice to kill Listeria. Together, these data suggest that the constant presence of low levels of IFNy driven by latent virus infection results in an increase in the basal expression levels of downstream effector molecules and the priming of cells for the enhanced immediate killing of Listeria upon infection, as well as for a more rapid further induction of IFNy and its effector molecules in response to the bacterial challenge. In this sense, chronic virus infection sets the level of innate immunity to subsequent infection.

HOIL-1 KO mice bred in a high grade barrier facility failed to exhibit certain phenotypes of HOIL-1 deficient patients, specifically by not exhibiting baseline hyper-inflammation and by displaying a striking immunodeficiency out of proportion to that observed in some humans with bi-allelic mutations in RBCK1 (HOIL1). Most humans are infected life-long with multiple herpesviruses (Virgin et al., 2009; Virgin, 2014), and many also carry other chronic or latent infections such as tuberculosis. Importantly, we observed complementation of immunodeficiency to Listeria by chronic herpesvirus infection in four different strains of immunodeficient mice, revealing virus infection as one possible environmental factor that might alter the genotype-phenotype relationship for patients with mutations in immune system genes. HOIL-1 KO mice chronically infected with either a herpesvirus or M. tuberculosis also exhibited increases in some of the same cytokines reported in the serum of HOIL-1 deficient humans. At least three of the HOIL-1 mutant patients were infected with at least one herpesvirus (Boisson et al., 2012), and it is likely that other chronic infections were present. However, in the absence of data regarding the complete infection status of the HOIL-1 mutant patients, the relevance of the mouse studies to the human phenotypes is unclear. Nevertheless, perhaps the presence of the virome, and potentially variations in the virome or other chronic infections between people, confers significant phenotypic variation by complementing mutations in host genes responsible for innate immunity (Virgin, 2014).

The genes involved in immunity and inflammation are the most rapidly evolving in the mammalian genome (Lindblad-Toh et al., 2011; Casanova et al., 2013; Quintana-Murci and Clark, 2013). Survival from infection requires a trade-off between alleles that promote or limit inflammation to balance immunity vs immunopathology. We speculate that the virome or other chronic infections hide or enhance the effects of genetic variations in immune responsiveness by complementing chromosomal variations in immune response genes. As the nature of the virome changes in persons growing up in different cultural and economic environments, it is possible that the immunophenotype of the host changes, and the beneficial or deleterious effects of existing genetic variation are unmasked by removal of complementation provided by chronic virus infection. It is also plausible that the striking autoinflammation observed in humans with a variety of immune defects could be due to even well controlled herpesvirus infection alone or in combination with other chronic infections. Our data suggest 
that analysis of the metagenome, including the virome, may be of value in linking human phenotype and genotype (Virgin, 2014; Virgin and Todd, 2011). Recent rapid advances in sequencing and analysis of the metagenome will make integration of data from the virome into human genetic studies practical (Virgin, 2014).

\section{Materials and methods}

\section{Mice}

HOIL-1 KO mice, with null mutations in the Rbck1 gene that encodes HOIL-1, have been described previously (Tokunaga et al., 2009). C57BL/6J mice or HOIL-1 WT littermates were used as wild type controls. Rag $1^{-/-}$mice were purchased from The Jackson Laboratory (Bar Harbor, ME) and bred to HOIL-1 KO mice. $116^{-/-}$mice were purchased from The Jackson Laboratory. Caspase 1;Caspase 11-deficient mice with or without a Caspase 11 transgene were kindly provided by Vishva Dixit, Genentec, San Francisco USA. All mice were housed and bred at Washington University in Saint Louis in specific pathogen-free conditions in accordance with Federal and University guidelines and protocols were approved by the Animal Studies Committee of Washington University under protocol number 20140244. Mice were inoculated between 8 and 11 weeks of age.

\section{In vivo infections}

L. monocytogenes wild type strain EGD was used for this study. Listeria glycerol stocks were stored at $-80{ }^{\circ} \mathrm{C}$, and thawed and diluted into PBS for intraperitoneal (i.p.) injection into mice. To determine tissue burden, spleens and livers were homogenized in $10 \mathrm{ml} \mathrm{PBS}$ containing $0.05 \%$ Triton X-100 and serial dilutions were plated on brain heart infusion agar plates. Listeria CFU were counted after overnight growth at $37^{\circ} \mathrm{C}$. Small sections of spleen and liver were also fixed in $10 \%$ buffered formalin for histological analysis.

The type II Prugniaud strain of T. gondii expressing a firefly luciferase (PRU-Fluc-GFP, provided by J. Boothroyd, Stanford University, Palo Alto, CA) (Saeij et al., 2005) was used in all in vivo T. gondii experiments. Tachyzoites were grown by 2-day serial passage in human foreskin fibroblasts. For infections, freshly egressed parasites were filtered, counted, and injected i.p. into mice.

Mice were with inoculated orally with $2 \times 10^{9}$ CFU C. rodentium strain DBS100 (ATCC, Manassas, VA) from a fresh culture and monitored for morbidity and mortality.

MHV68 WUMS (ATCC VR1465), MHV68 ORF73.stop and YHV68 M3-Fluc were passaged and titered by plaque assay on $\mathrm{NIH} 3 \mathrm{~T} 12$ cells. Virus stocks were stored at $-80^{\circ} \mathrm{C}$, and thawed and diluted into PBS for i.p. or intranasal (i.n.) inoculation of mice. For experiments involving MHV68 ORF73.stop, i.n. inoculation with $5 \times 10^{4} \mathrm{CFU}$ was performed due to the low titer of the virus stock. To determine yHV68 titers in tissues, organs were placed in $1 \mathrm{ml}$ of complete DMEM and frozen at $-80^{\circ} \mathrm{C}$. Samples were thawed prior to disruption with silica beads and virus titration by plaque assay.

Before infection, exponentially replicating M. tuberculosis Erdman strain bacteria were washed in PBS + $0.05 \%$ Tween 80 , and sonicated to disperse clumps. Mice were exposed to $8 \times 10^{7} \mathrm{CFU}$ of M. tuberculosis in an Inhalation Exposure System (Glas-Col, Terre Haute, IN), which delivers $~ 100$ bacteria to the lung per animal. After $24 \mathrm{hr}$ post infection, two mice per group were sacrificed, and lungs were harvested to determine infection efficiency, which was about $100 \mathrm{CFU} /$ lung/mouse. Experimental mice were sacrificed 70 days after infection, and lungs and spleen were harvested for CFU, and serum was collected for cytokine analysis. Bacterial burdens were determined by plating serial dilutions of lung and spleen homogenates onto $7 \mathrm{H} 10$ agar plates and incubated at $37^{\circ} \mathrm{C}$ in $5 \% \mathrm{CO}_{2}$ for 3 weeks prior to counting colonies.

\section{MHV68 ex vivo limiting dilution assay for reactivation from latency and limiting dilution PCR for viral genomes}

MHV68 reactivation from latency and preformed virus was assayed as described previously (Weck et al., 1996). Briefly, peritoneal exudate cells were plated in twofold serial dilutions (24-wells per dilution) onto permissive mouse embryonic fibroblast (MEF) monolayers and scored for cytopathic effect (CPE) 3 weeks later. Reactivation of lytic virus from a peritoneal cell leads to complete CPE of the MEF monolayer. To measure preformed infectious virus in the sample, parallel samples of cells were mechanically disrupted to kill the cells but keep any infectious virus intact. These samples were plated and scored as described above. Using the Poisson distribution, CPE in $63.2 \%$ of wells indicates that one reactivation event is likely to have occurred per well, and is used to determine the frequency of reactivating cells in the sample. 
To determine the frequency of cells harboring viral genome, peritoneal cells were assayed by nested PCR for viral genome as described previously (Weck et al., 1999). The detection of PCR product in $63.2 \%$ of wells indicates that one genome was present per well.

\section{Cells and infections}

Primary bone marrow-derived macrophages were prepared as described previously (Hwang et al., 2012). Briefly, bone marrow was extracted from mouse femurs and allowed to differentiate in DMEM containing 10\% FBS, 10\% CMG14-12 cell-conditioned media as a source of M-CSF (Takeshita et al., 2000), 5\% horse serum, $1 \mathrm{mM}$ sodium pyruvate and $2 \mathrm{mM} \mathrm{L-Glutamine} \mathrm{for} 7$ days.

For cytokine and transcript analyses following Listeria infection of macrophages, adherent cells were scraped and seeded in tissue culture-treated plates in the absence of M-CSF. After 3 days, macrophages were infected with $10 \% / \mathrm{ml}$ Listeria in the presence or absence of $100 \mathrm{U} / \mathrm{ml} \mathrm{IFNy.} 2 \mathrm{hr}$ postinfection, $50 \mathrm{U} / \mathrm{ml}$ Penicillin and $50 \mu \mathrm{g} / \mathrm{ml}$ streptomycin were added to kill the Listeria. Cell supernatants were harvested at indicated times and frozen at $-80^{\circ} \mathrm{C}$ prior to cytokine analysis. Cells were lyzed in TRI-Reagent for RNA extraction.

For Listeria growth/killing assays, macrophages were seeded in non-tissue culture treated dishes in the absence of M-CSF. After 1 day, cells were treated with $300 \mu / \mathrm{ml} \mathrm{IFNy}$ or untreated, and $48 \mathrm{hr}$ later scraped replated on sterile coverslips. After $3 \mathrm{hr}$, cells were infected with $105 / \mathrm{ml}$ Listeria from an overnight standing culture and centifuged to synchronize the infection. $50 \mu \mathrm{g} / \mathrm{ml}$ gentamycin was added after $30 \mathrm{~min}$ to kill extracellular bacteria. At the indicated times, coverslips were washed with warm PBS, then lyzed in $10 \mathrm{ml}$ cold water to release the bacteria. Serial dilutions were plated on brain heart infusion agar plates, and Listeria CFU were counted after overnight growth at $37^{\circ} \mathrm{C}$.

For MHV68 growth analysis, adherent cells were scraped and seeded in tissue culture-treated plates in the presence of M-CSF. After 2 days, macrophages were treated with $0.1 \mathrm{U} / \mathrm{ml} \mathrm{IFNy}$ or untreated, and $12 \mathrm{hr}$ later infected with MHV68 at a multiplicity of infection (MOI) of 0.05 for $1 \mathrm{hr}$ with occasional rocking at $37^{\circ} \mathrm{C}$ and $5 \% \mathrm{CO}_{2}$. Cells were washed once with medium and incubated in DMEM supplemented with $10 \% \mathrm{FBS}$ and $2 \mathrm{mM} \mathrm{L}$-glutamine (with or without $0.1 \mathrm{U} / \mathrm{ml} \mathrm{IFNy}$ ) for the indicated period of time at $37^{\circ} \mathrm{C}$ and $5 \% \mathrm{CO}_{2}$, before being frozen at $-80{ }^{\circ} \mathrm{C}$. Virus titers were determined by plaque assay following two freeze-thaw cycles.

\section{Analysis of listericidal activity of peritoneal cells}

Cells were flushed from the peritoneum of mice that had been mock infected or infected with MHV68 for 32 days with ice cold DMEM containing $10 \%$ FBS and $2 \mathrm{mM} \mathrm{L-Glutamine.} 5 \times 10^{5}$ cells were plated on glass coverslips in 24 well plates in duplicate wells per timepoint and allowed to adhere overnight. Non-adherent cells were washed away with warm medium, and the remaining cells were infected with $10^{5}$ CFU Listeria from a overnight standing culture by spinocculation at $600 \times \mathrm{g}$ for $10 \mathrm{~min}$ at room temperature, and then incubated at $37^{\circ} \mathrm{C}$ and $5 \% \mathrm{CO}_{2} .50 \mu \mathrm{g} / \mathrm{ml}$ gentamycin was added after $30 \mathrm{~min}$ to kill extracellular bacteria. Coverslips were washed in warm PBS prior to hypotonic lysis of the cells in ice cold water to release the bacteria. Serial dilutions were plated on brain heart infusion agar plates, and Listeria CFU were counted after overnight growth at $37^{\circ} \mathrm{C}$.

\section{Generation of bone marrow chimeric mice}

Recipient mice were exposed to 1200 rad of whole body irradiation, and injected intravenously with 10 million whole bone marrow cells from donor mice. Mice were allowed to reconstitute for 8 to 10 weeks before Listeria challenge. Mice were bled at 7 weeks post-irradiation to determine percent chimerism. Genomic DNA was isolated from peripheral blood and analyzed by quantitative real-time PCR (qRTPCR) for the presence of Rbck1/Hoil1 intron 7 (in control cells; 5'-ATG CTG GAG TAG AGG CTG GA-3' and 5'-TGA CTG CTG CTT GGA GAG TG-3'), or the neomycin-resistance cassette (in HOIL-1 KO cells; 5'-CAA GAT GGA TTG CAC GCA GG-3' and 5'-GCA GCC GAT TGT CTG TTG TG-3'). Rag2 was used as a normalization control (5'-GGG AGG ACA CTC ACT TGC CAG TA-3' and 5'-AGT CAG GAG TCT CCA TCT CAC TGA-3').

\section{T. gondii Pru-luc in vivo luciferase imaging}

Imaging was performed as described previously (Saeij et al., 2005). Briefly, mice were injected i.p. with $150 \mathrm{mg} / \mathrm{kg}$ D-Luciferin (Biosynth AG, Switzerland) and allowed to remain active for $5 \mathrm{~min}$. Animals were subsequently anesthetized with $2 \%$ isoflurane for $5 \mathrm{~min}$ and then imaged with a Xenogen IVIS 
200 machine (Caliper Life Sciences, Hopkinton, MA). Data were analyzed using Living Image software (Caliper Life Sciences).

\section{Flow cytometry}

Peritoneal exudate cells were harvested by peritoneal lavage with $10 \mathrm{ml}$ ice cold FACS buffer (PBS supplemented with $2 \% \mathrm{FBS}$ and $50 \mathrm{U} / \mathrm{ml}$ Penicillin and $50 \mu \mathrm{g} / \mathrm{ml}$ Streptomycin). Splenocytes were isolated by filtering through two $100 \mu \mathrm{m}$ cell strainers into $10 \mathrm{ml}$ ice cold FACS buffer. Residual red blood cells were lysed with Red Blood Cell lysis buffer (Sigma, St Louis, MO), counted and stained for flow cytometry.

Cells were incubated with FACS buffer plus 1\% rat serum, 1\% hamster serum and 1\% Fc-block for $15 \mathrm{~min}$. Surface staining was performed for $30 \mathrm{~min}$ at room temperature. Cells were then washed and fixed with $2 \%$ formaldehyde. Cells were analyzed on an LSRII or LSR Fortessa flow cytometer (BD, Franklin Lakes, NJ) and the data were analyzed using FlowJo software (Tree Star, Inc, Ashland, OR). The following antibodies were used: anti-CD3e (clone 145-2C11, Biolegend, San Diego, CA), anti-CD4 (clone RM4-5, BD Pharmingen), anti-CD8 (clone 53-6.7, Biolegend), anti-lgM (clone II/41, BD Pharmingen), anti-CD19 (clone 6D5, Biolegend), anti-NK1.1 (clone PK136, BD Pharmingen), anti-NKp46 (clone 29A1.4, eBioscience, San Diego, CA), anti-Ly6C (clone HK1.4, Biolegend), anti-Ly6G (clone 1A8, Biolgend, anti-CD11b (clone M1/70, BD Pharmingen), anti-F4/80 (clone BM8, Biolegend).

\section{Cytokine analysis}

Cytokines in mouse serum and cell supernatants were quantitated using a custom Procarta Immunoassay Kit (Affymetrix, Santa Clara, CA) and analyzed on a Bio-Plex 200 System (BioRad, Hercules, CA) or by ELISA (BD, Franklin Lakes, NJ), respectively, according to the manufacturers' instructions.

\section{Quantitative reverse transcriptase-PCR}

Spleen sections were homogenized, and macrophages were lysed in TRI-Reagent (Sigma), and processed according to the manufacturer's instructions to isolate total RNA. RNA was isolated from peritoneal cells using RNeasy mini kit (Qiagen, Netherlands). RNA samples were treated with Turbo DNA-free DNase (Ambion, Austin, TX) prior to first strand cDNA synthesis with ImProm-II (Promega, Madison, WI) and random hexamer primers. Quantitative PCR was performed on a StepOnePlus machine using Power SYBR Green master mix (Applied Biosystems, Waltham, MA) and primers specific for ribosomal protein S29 (Rps29; 5'-AGC AGC TCT ACT GGA GTC ACC-3' and 5'-AGG TCG CTT AGT CCA ACT TAA TG-3'), Rbck1/Hoil-1 (5'-ATT CGG CGG AAT GGA GAC GG-3' and 5'-CTG GTT GGT CCT GGG CTT CG-3'), Trib3 (5'-CAC ACT GCC ACA AGC ACG GG-3' and 5'-CAC GCA GGC ATC TTC CAG G-3'), Tbc1d20 (5'-TGA GGG AGG GCT CCT GAC TG-3' and 5'-AGC AGC ACT TGC TGG TAG TCC-3'), $1112 b$ (5'-GCA CGG CAG CAG AAT AAA TAT GAG-3' and 5'-TTC AAA GGC TTC ATC TGC AAG TTC-3'), Tnf (5'-GGG TGA TCG GTC CCC AAA GG-3' and 5'- CTG AGT GTG AGG GTC TGG GC-3'), 116 (5'-GCC AGA GTC CTT CAG AGA GAT ACA-3' and 5'-CTT GGT CCT TAG CCA CTC CTT C-3'), Ifng (5'-ATG AAC GCT ACA CAC TGC ATC-3' and 5'-CCA TCC TTT TGC CAG TTC CTC-3') and iNos (Nos2) (5'-GTT CTC AGC CCA ACA ATA CAA GA-3' and 5'-GTG GAC GGG TCG ATG TCA C-3'). Transcript levels were analyzed using the $\triangle \Delta C_{T}$ method, with Rps 29 as the reference gene.

\section{Histology}

Tissues were fixed in $10 \%$ buffered formalin followed by $70 \%$ ethanol, paraffin embedded, sectioned and stained with Periodic acid-Schiff (PAS).

\section{Mouse blood work}

Alanine aminotransferase and aspartate aminotransferase were measured on a Liasys 330 (AMS Diagnostics, Weston, FL), complete blood counts were measured on a Hemavet 1700 (Drew Scientific, Waterbury, CT), and white blood cell differential counts were performed by Washington University Division of Comparative Medicine Animal Diagnostic Laboratory staff.

\section{Statistical analyses}

Statistical significance was determined using GraphPad Prism software. The specific tests performed are noted in the figure legends. 


\section{Acknowledgements}

We would like to acknowledge D Kreamalmeyer, JS Lee, Q Wang, CY Liu, Q Lu, M T Baldridge, T J Nice, the Washington University Department of Comparative Medicine Animal Diagnostic Laboratory and the Digestive Diseases Research Core Center for technical assistance, and ER Unanue for critical discussions and reading of the manuscript. We would like to thank Vishva Dixit and Genentec (San Francisco, CA) for providing the Caspase-1/Caspase-11 mutant mice containing a Caspase-11 transgene. HWV was funded by the Crohn's and Colitis Foundation Genetics Initiative grant \#274415, Broad Foundation grant \#IBD-0357, U19 Al109725 and R01 Al084887. BTE is supported by a Burroughs Wellcome Fund Career Award for Medical Scientists, a Basil O' Connor Starter Scholar Research Award from the March of Dimes Foundation, and a grant from the Edward Mallinckrodt Jr Foundation. JLC was funded by NIAID grant \#5P01AI061093, NIH grant \#8UL1TR000043 from the National Center for Research Resources and the National Center for Advancing Sciences, and the St. Giles Foundation. LDS was funded by grant \# Al036629. JAC was funded by grant \#AI062832. CLS is supported by a Beckman Young Investigator Award from the Arnold and Mabel Beckman Foundation. JMK is supported by a National Science Foundation Graduate Research Fellowship DGE-1143954 and the NIGMS Cell and Molecular Biology Training Grant GM007067.

\section{Additional information}

\begin{tabular}{|c|c|c|}
\hline \multicolumn{3}{|l|}{ Funding } \\
\hline Funder & Grant reference number & Author \\
\hline $\begin{array}{l}\text { Crohn's and Colitis Foundation } \\
\text { of America }\end{array}$ & $\begin{array}{l}\text { Genetics Initiative } \\
\text { grant } 274415\end{array}$ & Herbert W Virgin \\
\hline Broad Foundation & IBD-0357 & Herbert W Virgin \\
\hline National Institutes of Health & U19 Al109725 & Herbert W Virgin \\
\hline Burroughs Wellcome Fund & $\begin{array}{l}\text { Career Award for } \\
\text { Medical Scientists }\end{array}$ & Brian T Edelson \\
\hline March of Dimes Foundation & $\begin{array}{l}\text { Basil O'Conner Starter } \\
\text { Scholar Research Award }\end{array}$ & Brian T Edelson \\
\hline Edward Mallinckrodt Jr Foundation & Private Grant & Brian T Edelson \\
\hline National Institutes of Health & R01 Al084887 & Herbert W Virgin \\
\hline $\begin{array}{l}\text { National Institute of Allergy and } \\
\text { Infectious Diseases }\end{array}$ & 5P01 Al061093 & Jean-Laurent Casanova \\
\hline $\begin{array}{l}\text { National Center for Research } \\
\text { Resources }\end{array}$ & 8UL1TR000043 & Jean-Laurent Casanova \\
\hline National Institutes of Health & Al036629 & L David Sibley \\
\hline National Institutes of Health & Al062832 & Javier A Carrero \\
\hline $\begin{array}{l}\text { Arnold and Mabel Beckman } \\
\text { Foundation }\end{array}$ & $\begin{array}{l}\text { Beckman Young } \\
\text { Investigator Award }\end{array}$ & Christina L Stallings \\
\hline National Science Foundation & DGE-1143954 & Jacqueline M Kimmey \\
\hline $\begin{array}{l}\text { National Institute of General } \\
\text { Medical Sciences }\end{array}$ & GM007067 & Jacqueline M Kimmey \\
\hline
\end{tabular}

The funders had no role in study design, data collection and interpretation, or the decision to submit the work for publication.

Author contributions

DAM, Conception and design, Acquisition of data, Analysis and interpretation of data, Drafting or revising the article; TAR, Conception and design, Acquisition of data, Analysis and interpretation of data; JMK, LAW, CS, Acquisition of data, Analysis and interpretation of data; XZ, AK, ED, Acquisition of data, Analysis and interpretation of data, Drafting or revising the article; JAC, BTE, LDS, CLS, Conception and design, Analysis and interpretation of data; BB, EL, Al, CP, Analysis and interpretation of data, Contributed unpublished essential data or reagents; $\mathrm{MC}$, Conception and design; J-LC, Conception and design, Analysis and interpretation of data, Contributed unpublished 
essential data or reagents; KI, Conception and design, Contributed unpublished essential data or reagents; HWV, Conception and design, Analysis and interpretation of data, Drafting or revising the article

Ethics

Animal experimentation: All mice were housed and bred at Washington University in Saint Louis in specific pathogen-free conditions in accordance with Federal and University guidelines and protocols were approved by the Animal Studies Committee of Washington University under protocol number 20140244.

\section{References}

Barton E, Mandal P, Speck SH. 2011. Pathogenesis and host control of gammaherpesviruses: lessons from the mouse. Annual Review of Immunology 29:351-397. doi: 10.1146/annurev-immunol-072710-081639.

Barton ES, White DW, Cathelyn JS, Brett-McClellan KA, Engle M, Diamond MS, Miller VL, Virgin HW. 2007. Herpesvirus latency confers symbiotic protection from bacterial infection. Nature 447:326-329. doi: 10.1038/ nature05762.

Belkaid Y, Hand TW. 2014. Role of the Microbiota in Immunity and Inflammation. Cell 157:121-141. doi: 10.1016/j.cell.2014.03.011.

Boisson B, Laplantine E, Prando C, Giliani S, Israelsson E, Xu Z, Abhyankar A, Israel L, Trevejo-Nunez G, Bogunovic D, Cepika AM, Macduff D, Chrabieh M, Hubeau M, Bajolle F, Debré M, Mazzolari E, Vairo D, Agou F, Virgin HW, Bossuyt X, Rambaud C, Facchetti F, Bonnet D, Quartier P, Fournet JC, Pascual V, Chaussabel D, Notarangelo LD, Puel A, Israel A, Casanova JL, Picard C. 2012. Immunodeficiency, autoinflammation and amylopectinosis in humans with inherited HOIL-1 and LUBAC deficiency. Nature Immunology 13:1178-1186. doi: 10.1038/ni.2457.

Casanova JL, Abel L, Quintana-Murci L. 2013. Immunology taught by human genetics. Cold Spring Harbor Symposia on Quantitative Biology 78:157-172. doi: 10.1101/sqb.2013.78.019968.

Damgaard RB, Nachbur U, Yabal M, Wong WW, Fiil BK, Kastirr M, Rieser E, Rickard JA, Bankovacki A, Peschel C, Ruland J, Bekker-Jensen S, Mailand N, Kaufmann T, Strasser A, Walczak H, Silke J, Jost PJ, Gyrd-Hansen M. 2012. The ubiquitin ligase XIAP recruits LUBAC for NOD2 signaling in inflammation and innate immunity. Molecular Cell 46:746-758. doi: 10.1016/j.molcel.2012.04.014.

Edelson BT, Unanue ER. 2002. MyD88-dependent but Toll-like receptor 2-independent innate immunity to Listeria: no role for either in macrophage listericidal activity. The Journal of Immunology 169:3869-3875. doi: 10.4049/jimmunol.169.7.3869.

Gerlach B, Cordier SM, Schmukle AC, Emmerich CH, Rieser E, Haas TL, Webb Al, Rickard JA, Anderton H, Wong WW, Nachbur U, Gangoda L, Warnken U, Purcell AW, Silke J, walczak H. 2011. Linear ubiquitination prevents inflammation and regulates immune signalling. Nature 471:591-596. doi: 10.1038/nature09816.

Haas TL, Emmerich CH, Gerlach B, Schmukle AC, Cordier SM, Rieser E, Feltham R, Vince J, Warnken U, Wenger T, Koschny R, Komander D, Silke J, Walczak H. 2009. Recruitment of the linear ubiquitin chain assembly complex stabilizes the TNF-R1 signaling complex and is required for TNF-mediated gene induction. Molecular Cell 36:831-844. doi: 10.1016/j.molcel.2009.10.013.

Haque A, Rachinel N, Quddus MR, Haque S, Kasper LH, Usherwood E. 2004. Co-infection of malaria and gammaherpesvirus: exacerbated lung inflammation or cross-protection depends on the stage of viral infection. Clinical and Experimental Immunology 138:396-404. doi: 10.1111/j.1365-2249.2004.02652.x.

HogenEsch H, Janke S, Boggess D, Sundberg JP. 1999. Absence of Peyer's patches and abnormal lymphoid architecture in chronic proliferative dermatitis (cpdm/cpdm) mice. The Journal of Immunology 162:3890-3896.

Hostager BS, Kashiwada M, Colgan JD, Rothman PB. 2011. HOIL-1L interacting protein (HOIP) is essential for CD40 signaling. PLOS ONE 6:e23061. doi: 10.1371/journal.pone.0023061.

Hwang S, Maloney NS, Bruinsma MW, Goel G, Duan E, Zhang L, Shrestha B, Diamond MS, Dani A, Sosnovtsev SV, Green KY, Lopez-Otin C, Xavier RJ, Thackray LB, Virgin HW. 2012. Nondegradative role of Atg5-Atg12/ Atg16L1 autophagy protein complex in antiviral activity of interferon gamma. Cell Host \& Microbe 11:397-409. doi: 10.1016/j.chom.2012.03.002.

Ikeda F, Deribe YL, Skanland SS, Stieglitz B, Grabbe C, Franz-Wachtel M, van Wijk SJ, Goswami P, Nagy V, Terzic J, Tokunaga F, Androulidaki A, Nakagawa T, Pasparakis M, Iwai K, Sundberg JP, Schaefer L, Rittinger K, Macek B, Dikic I. 2011. SHARPIN forms a linear ubiquitin ligase complex regulating NF-kappaB activity and apoptosis. Nature 471:637-641. doi: 10.1038/nature09814.

Kayagaki N, Wong MT, Stowe IB, Ramani SR, Gonzalez LC, Akashi-Takamura S, Miyake K, Zhang J, Lee WP, Muszynski A, Forsberg LS, Carlson RW, Dixit VM. 2013. Noncanonical inflammasome activation by intracellular LPS independent of TLR4. Science 341:1246-1249. doi: 10.1126/science.1240248.

Kopf M, Baumann H, Freer G, Freudenberg M, Lamers M, Kishimoto T, Zinkernagel R, Bluethmann H, Kohler G. 1994. Impaired immune and acute-phase responses in interleukin-6-deficient mice. Nature 368:339-342. doi: 10.1038/368339a0.

Lindblad-Toh K, Garber M, Zuk O, Lin MF, Parker BJ, Washietl S, Kheradpour P, Ernst J, Jordan G, Mauceli E, Ward LD, Lowe CB, Holloway AK, Clamp M, Gnerre S, Alfoldi J, Beal K, Chang J, Clawson H, Cuff J, Di Palma F, Fitzgerald S, Flicek P, Guttman M, Hubisz MJ, Jaffe DB, Jungreis I, Kent WJ, Kostka D, Lara M, Martins AL, Massingham T, Moltke I, Raney BJ, Rasmussen MD, Robinson J, Stark A, Vilella AJ, Wen J, Xie X, Zody MC, 
Broad Institute Sequencing Platform and whole Genome Assembly team, Baldwin J, Bloom T, Chin CW, Heiman D, Nicol R, Nusbaum C, Young S, Wilkinson J, Worley KC, Kovar CL, Muzny DM, Gibbs RA, Baylor College of Medicine Human Genome Sequencing Center Sequencing Team, Cree A, Dihn HH, Fowler G, Jhangiani S, Joshi V, Lee S, Lewis LR, Nazareth LV, Okwuonu G, Santibanez J, Warren WC, Mardis ER, Weinstock GM, Wilson RK, Genome Institute at Washington University, Delehaunty K, Dooling D, Fronik C, Fulton L, Fulton B, Graves T, Minx P, Sodergren E, Birney E, Margulies EH, Herrero J, Green ED, Haussler D, Siepel A, Goldman N, Pollard KS, Pedersen JS, Lander ES, Kellis M. 2011. A high-resolution map of human evolutionary constraint using 29 mammals. Nature 478:476-482. doi: 10.1038/nature10530.

Moorman NJ, Willer DO, Speck SH. 2003. The gammaherpesvirus 68 latency-associated nuclear antigen homolog is critical for the establishment of splenic latency. Journal of Virology 77:10295-10303. doi: 10.1128/ JVI.77.19.10295-10303.2003.

Nguyen Y, Mcguffie BA, Anderson VE, Weinberg JB. 2008. Gammaherpesvirus modulation of mouse adenovirus type 1 pathogenesis. Virology 380:182-190. doi: 10.1016/j.virol.2008.07.031.

Nilsson J, Schoser B, Laforet P, Kalev O, Lindberg C, Romero NB, Dávila López M, Akman HO, Wahbi K, Iglseder S, Eggers C, Engel AG, Dimauro S, Oldfors A. 2013. Polyglucosan body myopathy caused by defective ubiquitin ligase RBCK1. Annals of Neurology 74:914-919. doi: 10.1002/ana.23963.

Quintana-Murci L, Clark AG. 2013. Population genetic tools for dissecting innate immunity in humans. Nature Reviews Immunology 13:280-293. doi: 10.1038/nri3421.

Rodgers MA, Bowman JW, Fujita H, Orazio N, Shi M, Liang Q, Amatya R, Kelly TJ, Iwai K, Ting J, Jung JU. 2014. The linear utiquitin assembly complex (LUBAC) is essential for NLRP3 inflammasome activation. The Journal of Experimental Medicine 211:1333-1347. doi: 10.1084/jem.20132486.

Saeij JP, Boyle JP, Grigg ME, Arrizabalaga G, Boothroyd JC. 2005. Bioluminescence imaging of Toxoplasma gondii infection in living mice reveals dramatic differences between strains. Infection and Immunity 73:695-702. doi: 10.1128/IAl.73.2.695-702.2005.

Sarawar SR, Brooks JW, Cardin RD, Mehrpooya M, Doherty PC. 1998. Pathogenesis of murine gammaherpesvirus-68 infection in interleukin-6- deficient mice. Virology 249:359-366. doi: 10.1006/viro.1998.9309.

Sasaki Y, Sano S, Nakahara M, Murata S, Kometani K, Aiba Y, Sakamoto S, Watanabe Y, Tanaka K, Kurosaki T, Iwai K. 2013. Defective immune responses in mice lacking LUBAC-mediated linear ubiquitination in $B$ cells. The EMBO Journal 32:2463-2476. doi: 10.1038/emboj.2013.184.

Sauer JD, Pereyre S, Archer KA, Burke TP, Hanson B, Lauer P, Portnoy DA. 2011. Listeria monocytogenes engineered to activate the Nlrc4 inflammasome are severely attenuated and are poor inducers of protective immunity. Proceedings of the National Academy of Sciences of USA 108:12419-12424. doi: 10.1073/ pnas. 1019041108.

Seymour RE, Hasham MG, Cox GA, Shultz LD, Hogenesch H, Roopenian DC, Sundberg JP. 2007. Spontaneous mutations in the mouse Sharpin gene result in multiorgan inflammation, immune system dysregulation and dermatitis. Genes and Immunity 8:416-421. doi: 10.1038/sj.gene.6364403.

Speck SH, Ganem D. 2010. Viral latency and its regulation: lessons from the gamma-herpesviruses. Cell Host \& Microbe 8:100-115. doi: 10.1016/j.chom.2010.06.014.

Takeshita S, Kaji K, Kudo A. 2000. Identification and characterization of the new osteoclast progenitor with macrophage phenotypes being able to differentiate into mature osteoclasts. Journal of Bone and Mineral Research 15:1477-1488. doi: 10.1359/jbmr.2000.15.8.1477.

Tian Y, Zhang Y, Zhong B, Wang YY, Diao FC, Wang RP, Zhang M, Chen DY, Zhai ZH, Shu HB. 2007. RBCK1 negatively regulates tumor necrosis factor- and interleukin-1-triggered NF-kappaB activation by targeting TAB2/3 for degradation. The Journal of Biological Chemistry 282:16776-16782. doi: 10.1074/jbc. M701913200.

Tokunaga F, Iwai K. 2012. LUBAC, a novel ubiquitin ligase for linear ubiquitination, is crucial for inflammation and immune responses. Microbes and Infection 14:563-572. doi: 10.1016/j.micinf.2012.01.011.

Tokunaga F, Nakagawa T, Nakahara M, Saeki Y, Taniguchi M, Sakata S, Tanaka K, Nakano H, Iwai K. 2011. SHARPIN is a component of the NF-kappaB-activating linear ubiquitin chain assembly complex. Nature 471:633-636. doi: 10.1038/nature09815.

Tokunaga F, Nishimasu H, Ishitani R, Goto E, Noguchi T, Mio K, Kamei K, Ma A, Iwai K, Nureki O. 2012. Specific recognition of linear polyubiquitin by $\mathrm{A} 20$ zinc finger 7 is involved in NF-kappaB regulation. The EMBO Journal 31:3856-3870. doi: 10.1038/emboj.2012.241.

Tokunaga F, Sakata S, Saeki Y, Satomi Y, Kirisako T, Kamei K, Nakagawa T, Kato M, Murata S, Yamaoka S, Yamamoto M, Akira S, Takao T, Tanaka K, Iwai K. 2009. Involvement of linear polyubiquitylation of NEMO in NF-kappaB activation. Nature Cell Biology 11:123-132. doi: 10.1038/ncb1821.

Tsuji NM, Tsutsui H, Seki E, Kuida K, Okamura H, Nakanishi K, Flavell RA. 2004. Roles of caspase-1 in Listeria infection in mice. International Immunology 16:335-343. doi: 10.1093/intimm/dxh041.

Unanue ER. 1997. Inter-relationship among macrophages, natural killer cells and neutrophils in early stages of Listeria resistance. Current Opinion in Immunology 9:35-43. doi: 10.1016/S0952-7915(97)80156-2.

Verhelst K, Carpentier I, Kreike M, Meloni L, Verstrepen L, Kensche T, Dikic I, Beyaert R. 2012. A20 inhibits LUBAC-mediated NF-kappaB activation by binding linear polyubiquitin chains via its zinc finger 7 . The EMBO Journal 31:3845-3855. doi: 10.1038/emboj.2012.240.

Virgin HW. 2014. The virome in mammalian physiology and disease. Cell 157:142-150. doi: 10.1016/j. cell.2014.02.032.

Virgin HW, Todd JA. 2011. Metagenomics and personalized medicine. Cell 147:44-56. doi: 10.1016/j. cell.2011.09.009. 
Virgin HW, Wherry EJ, Ahmed R. 2009. Redefining chronic viral infection. Cell 138:30-50. doi: 10.1016/j. cell.2009.06.036.

Wang K, Kim C, Bradfield J, Guo Y, Toskala E, Otieno FG, Hou C, Thomas K, Cardinale C, Lyon GJ, Golhar R, Hakonarson H. 2013. Whole-genome DNA/RNA sequencing identifies truncating mutations in RBCK1 in a novel Mendelian disease with neuromuscular and cardiac involvement. Genome Medicine 5:67. doi: 10.1186/gm471.

Weck KE, Barkon ML, Yoo LI, Speck SH, Virgin HW IV. 1996. Mature B cells are required for acute splenic infection, but not for establishment of latency, by murine gammaherpesvirus 68. Journal of Virology 70:6775-6780.

Weck KE, Kim SS, Virgin HW, Speck SH. 1999. Macrophages are the major reservoir of latent murine gammaherpesvirus 68 in peritoneal cells. Journal of Virology 73:3273-3283.

White DW, Keppel CR, Schneider SE, Reese TA, Coder J, Payton JE, Ley TJ, Virgin HW, Fehniger TA. 2010. Latent herpesvirus infection arms NK cells. Blood 115:4377-4383. doi: 10.1182/blood-2009-09-245464.

Williams MA, Schmidt RL, Lenz LL. 2012. Early events regulating immunity and pathogenesis during Listeria monocytogenes infection. Trends in Immunology 33:488-495. doi: 10.1016/j.it.2012.04.007.

Yager EJ, Szaba FM, Kummer LW, Lanzer KG, Burkum CE, Smiley ST, Blackman MA. 2009. gamma-Herpesvirusinduced Protection against bacterial infection is transient. Viral Immunology 22:67-71. doi: 10.1089/vim.2008.0086.

Zak DE, Schmitz F, Gold ES, Diercks AH, Peschon JJ, Valvo JS, Niemisto A, Podolsky I, Fallen SG, Suen R, Stolyar T, Johnson CD, Kennedy KA, Hamilton MK, Siggs OM, Beutler B, Aderem A. 2011. Systems analysis identifies an essential role for SHANK-associated RH domain-interacting protein (SHARPIN) in macrophage Toll-like receptor 2 (TLR2) responses. Proceedings of the National Academy of Sciences of USA 108:11536-11541. doi: 10.1073/ pnas. 1107577108. 